\title{
Spatio-Temporal Coupling Relationships between Rural Population and Farmland Change in Karst Mountainous Areas of Southwest China
}

\author{
Juan Huang ${ }^{1,2}$, Yangbing $\mathrm{Li}^{1 *}$, Qian $\mathrm{Xu}^{1}$, Tian $\mathrm{Shu}^{3,4}$, Sitao Peng ${ }^{1}$, \\ Lv Du ${ }^{5}$, Mengmeng Wang ${ }^{1}$ \\ ${ }^{1}$ School of Geography and Environmental Science, Guizhou Normal University, Guiyang Guizhou 550001, China \\ ${ }^{2}$ School of Tourism and Resource Environment, Qiannan Normal University for Nationalities, \\ Duyun Guizhou 558000, China \\ ${ }^{3}$ School of Karst Science, Guizhou Normal University, Guiyang 550001, China \\ ${ }^{4}$ Institute of Science and Technology Information, Guizhou Academy of Agricultural Sciences, \\ Guiyang 550006, China \\ ${ }^{5}$ College of Urban Planning and Architectural Engineering, Guiyang University, Guiyang 550002, China
}

Received: 14 January 2021

Accepted: 16 July 2021

\begin{abstract}
Population and farmland are the key elements in agricultural production and significant components of the rural population-land relationship. Spatial-temporal coupling changes to population and farmland in mountainous Karst areas across Southwest China can reveal the transformation and evolution of this relationship. Such findings provide a scientific basis for agricultural land regulation, ecological restoration, and rural revitalization. Features of the population and farmland change trend in Yinjiang County were analyzed together with spatial-temporal coupling characteristics. The driving forces affecting population data, land data and their relationship with each other were investigated using an elastic coefficient model. The results showed that between 1958-2016, both the rural population and farmland extent in the mountainous karst areas across Yinjiang County rose then fell, while the opposite trend was seen for per capita farmland area; further, the results showed that from 1958-2016, the spatial-temporal coupling relationships between the rural population and farmland change across Yin Jiang County were first non-coordinated but became coordinated over time; finally, the results indicated that factors driving the formation and development of the spatial-temporal coupling relationship were mainly attributable to the combined effects of natural environment, socio-economic conditions, policy, and changes in urban-rural relations. Results revealed that the spatial-temporal coupling relationships between the rural population and farmland had significantly changed over the last 60 years in mountainous karst areas across Southwest China and that there has been a transition in the population-land relationship in rural areas. Furthermore, the results strongly suggest that ecological
\end{abstract}

*e-mail: 1i-yapin@sohu.com 
restoration, farmland planning, and land resource redistribution should be introduced so that rural revitalization and a sustainable population-land relationship can be achieved.

Keywords: farmland change, population change, population-farmland elastic coefficient, spatio-temporal coupling relationships, karst trough valley area

\section{Introduction}

Since the beginning of agriculture, both global human population and resource consumption have grown synchronously [1]. This is specifically evident in traditional agricultural societies where farmers solely rely on the land for a living, which suggests therefore, an extreme dependence on land resources [2]. Agriculture emerged in the fertile plains, but as populations expanded farmers began to reclaim marginal land, such as hills and mountainous regions, in order to obtain extra food to meet growing demands. As a result, more and more forest and grasslands were converted into farmland [2-3] leading to significant land use and land cover change (LUCC).

Land use and land cover change is an important component of global environmental change, which means that it has attracted extensive attention and has become one of the core components of on the field of global environmental change [4]. The direct causes of LUCC are activities such as agriculture, forestry, and infrastructure development, and these changes are driven by complex social, political, economic, technological, cultural, biophysical, and demographic factors [4]. It is generally accepted that the various forms of population migration are the most important demographic factors to influence land use changes on the multi-decadal timescale [4-6].

Urbanization has meant that migration by rural populations to cities has become a global problem. This migration has led to a decrease in the rural proportion of the global population from $66.64 \%$ to $46.16 \%$ between 1960 and 2015, driven mainly by changes in Asia and Africa [7-8]. Large-scale rural migration has affected decision-making and the practical use of rural land, driving a significant transformation in land use, and resulting in a series of social and ecological effects [9].

Since "Reform and Opening Up" in 1978, China has also experienced a transition from a closed traditional agricultural society to an open globalized modern, industrial, and urban society [10-11]. As a result, rural areas have undergone significant changes, with the rural population falling from $89.4 \%$ to $40.42 \%$ of the total population between 1949 and 2018.

In China, farmland coverage reached its peak between 1978 and 1980, but then gradually decreased due to factors such as urban and ecological construction [12]. The de-agriculturization of farmland across large areas of China has affected the farmland area, traditional food production patterns, and food security of the country [13-16]. Rapid industrialization and urbanization has meant that it is now not necessary to produce food in mountainous areas [2]. Policies such as excessive land reclamation and forest shrinkage have been reversed and this has led to large increases of abandoned farmland; much of which has been restored back to forest [17]. The artificial disturbance of rural land in mountainous areas has recently decreased and the function of the land ecosystem has changed from degradation to restoration [2]. Population migration and land use transformation has also occurred in mountainous regions across France, Holland [18], and Puerto Rico [1].

The Karst area in Southwest China is one of the three largest Karst areas in the world [19-20]. Rocky desertification is the most concerning consequence of ecological degradation problem in Karst areas [20-21] and it is thought to be the result of a combination of natural conditions and unsustainable human activities [22-23]. Based on the 2007 Bulletin on the Status of Rocky Desertification in Karst Areas issued by the State Forestry Administration of China, $74 \%$ of the total rocky desertification land had been caused by human factors, such as a high population density, inappropriate farming methods, and excessive reclamation in Karst landscapes. In traditional agricultural societies, longterm high population pressure and incomes solely based on agricultural production forced farmers to reclaim uncultivated land for steep slope farming, which resultingly leads to rocky desertification [2425]. Over the recent years, the Southwestern Karst region has also undergone a transformation that has been driven by rapid industrialization and urbanization. In 2016, the urbanization rate for Karst areas in China reached $45.5 \%$. Furthermore, the migration of rural labour, de-agriculturalization of farmer livelihoods, poverty alleviation, and relocation of rural households have meant that a large proportion of the rural population have left the area and farmland has therefore become marginalized. The implementation of ecological conservation and restoration projects, such as the "Grain for Green Project" and the "Karst Rocky Desertification Control Project", have led to a decrease in farmer dependence on land, farmland abandonment, and rural hollowing [26]. These effects have driven the transformation of land use in the Karst mountainous areas with the degraded ecosystems now undergoing restoration. According to a report by the State Forestry Administration of China, the rocky desertification coverage in Karst areas has decreased from 12.96 million hectares in 2005 to 10.07 million hectares in 2016. This suggests that changes in rural population and livelihood patterns in Karst areas are important 
factors that drive changes in Karst land use and rock desertification. Therefore, it is important to explore the spatio-temporal evolution of rural populations and farmland in typical Karst mountainous areas to understand the changes in the rural population-land relationship in these areas across Southwest China.

In recent years, researches on rural population and arable land have made continuous progress. Related researches mainly focus on the single element of farmland and rural population. farmland elements include the transformation of farmland use [16], the evolution of farmland use landscape [13], and the marginalization of farmland in mountainous areas [27], etc.; rural population elements include rural population migration [28], the influence of rural population migration on urbanization [29] and rural decline [30]. Therefore, in the process of implementing rural revitalization, the relationship with the migration of the population must be well handled. In terms of research on the relationship between the rural population and farmland, relevant researches mainly focus on the impact of population non-agriculturalization [31] on land scale management and cultivated land use patterns [32], as well as the coupling relationship between farmland and labor [33]. The migration of the population has brought about a reduction in the utilization rate of farmland in many mountainous areas. Relevant studies in Italy [34], Austria [35], Ethiopia [36] and other places mainly focus on the abandonment of farmland and insufficient grazing caused by population decline, as well as the land degradation caused by the problem. In general, the current analysis of the distribution, evolution, mechanism and effects of farmland and rural population on a national scale and in specific regions has made significant progress. However, there are few studies on the coupling characteristics of the differences between rural population and farmland. China has a vast territory, and there are obvious imbalances in natural conditions and social and economic development. The changes in farmland and rural population also have their own internal differences. The coupling relationships between rural population and farmland change remain unclear at the spatial and temporal scales. Therefore, the research scale needs to be further deepened from the provincial and county scales to the village scale. Research based on the characteristics of multi-period coupling can better reflect and explain the micro-scale changes within the region.

Guizhou Province has the most widely distributed and vulnerable Karst region in Southwest China [37]. It is also a province where rural population migration and poverty rates are high [38]. Therefore, it is important to explore case studies of the spatiotemporal evolution of rural populations and farmland in Guizhou will have strong, practical significance for studies investigating land-use transformation and populationland relationships in karst mountain areas across Southwest China. This paper selected Yinjiang County, a typical karst trough valley area in Guizhou Province, as the research object, and used Population-Farmland Elastic Coefficient and coupling relationship types degree model to make a quantitative analysis of the spatio-temporal coupling relationship between rural population and farmland. Firstly, this paper determines the coupling relationship between rural population and farmland change on the basis of existing studies. secondly, analyze the coupling relationship between the rural population and farmland change by using county and village level data from 1958, 1973, 1990, 2000, 2010, and 2016; finally, we further explored the mechanism driving the coupling relationship between the rural population and farmland change in karst mountain areas and its effect on ecology and policies, with a view to providing support for ecological restoration, land space optimization, and rural revitalization in the karst areas of Southwest China.

\section{Materials and Methods}

\section{Study Region}

Yinjiang Tujia and Miao Autonomous County (Yinjiang for short) is located in northeastern Guizhou Province, China $\left(27^{\circ} 35^{\prime} 19^{\prime \prime}-28^{\circ} 20^{\prime} 32^{\prime \prime} \mathrm{N}, 108^{\circ} 17^{\prime} 52^{\prime \prime}-\right.$ $\left.108^{\circ} 48^{\prime} 18^{\prime \prime} \mathrm{E}\right)$. It is located in the transitional depression area between the Guizhou Plateau and the Sichuan Basin, with a total area of $1968.06 \mathrm{~km}^{2}$. Yinjiang County belongs to the Southwest Karst trough area, which is classified into four landform types based on its exposed lithology and elevation (Fig.1). The trough valley area accounts for $48.39 \%$ of the total area of the county. Two large trough valleys (the Langxi and Fengxiang) are located in the central-Southwestern part of the county. The area has a subtropical warm and humid monsoon climate with an average annual temperature of $16.8^{\circ} \mathrm{C}$, annual rainfall of about $1100 \mathrm{~mm}$, and high levels of biodiversity. Parts of the Fanjingshan World Natural Heritage site and the Fanjingshan National Nature Reserve are located in Yinjiang County. In addition, Yinjiang County is one of the 'special poverty counties' in the Wuling Mountain area and was listed as a national key ecological function zone in 2016.

The county currently governs 17 towns. At the end of 2016, the farmland area was $34,209.69 \mathrm{hm}^{2}$; the registered population was 452,200 ; the permanent population was 285,800 , of which the agricultural registered permanent population was 232,100 ; and the population density of the permanent population was 118 people per $\mathrm{km}^{2}$.

The trough valley and the non-trough valley areas in Yinjiang County are divided by the landform and the borders of the administrative villages [39]. There are 163 villages in the trough valley area and 188 in the nontrough valley area, accounting for $46.44 \%$ and $53.56 \%$ of the total village area in the county, respectively. The trough valley is further divided into dam villages and hillside villages. There are 57 dam villages and 

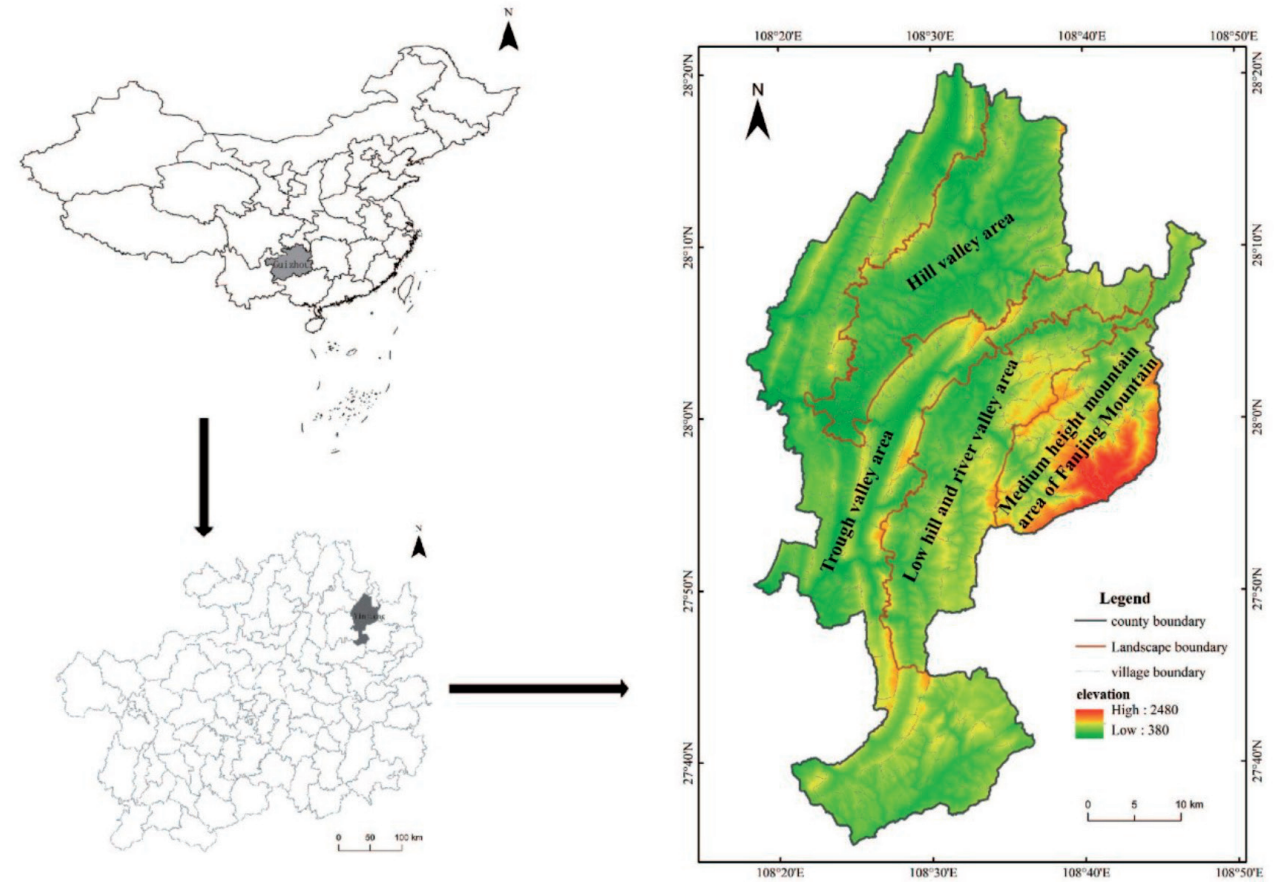

Fig. 1. Geographical location and geomorphology of the study area.

106 hillside villages, accounting for $34.97 \%$ and $65.03 \%$ of the total trough valley area, respectively. The same criteria were used to divide the non-trough areas. There are 74 dam villages and 114 hillside villages, accounting for $39.36 \%$ and $60.64 \%$ of the total nontrough area.

\section{Data Sources}

A farmland data set containing topographic maps, satellite imagery, and remote sensing image data was obtained. The data from 1958 was obtained from a 1:50,000 topographic map; the data in 1973 was taken from Landsat MSS images (resolution $60 \mathrm{~m}$ ); and the data in 1990, 2000, 2010, and 2016 was all obtained using Landsat TM Image (resolution $30 \mathrm{~m}$ ), and by selecting near-infrared, red, and green light bands and reverse standard false colours to synthesize the data source. The land use vector data for the six periods from 1958 to 2016 in the study area were obtained by integrally using the ArcMap platform, visual interpretation, and field surveys. The field investigation verified that the data interpretation accuracy reached more than $87 \%$, which was deemed satisfactory for farmland analyses.

Statistical yearbooks and census data were used to obtain data on the rural population size through time. The data were usually determined by agricultural household registrations and the rural permanent population as classified by residential registration [40]. The rural permanent population can accurately reflect the changing population-land relationship. Thus, the rural population in this study denotes the rural permanent population. The rural population data covered 1958 and 1973 and were derived from the Guizhou Sixty Years 1949-2009 dataset. It was interpolated using village data from the third census of Yinjiang County. The rural population data from 1990, 2000, and 2010 were part of the fourth, fifth, and sixth censuses of Yinjiang County, respectively, and the 2016 rural population data were derived from the Statistical Yearbook of Yinjiang County. The research time span was large and the administrative divisions in Yinjiang County had been adjusted, which meant that the administrative units at the village level in the research area took the current village administrative units in Yinjiang County as the standard. The data showed that there were 351 villages in total. The rural population data for the changed administrative villages were then adjusted accordingly. With the exception of the Fanjingshan National Nature Reserve data, this study was able to obtain the basic data for the rural population and the farmland associated with 347 research villages. A spatial analysis database was established based on the ArcGIS software platform to analyze the change rate and the spatio-temporal coupling characteristics between the rural population and farmland change.

\section{Research Methods}

\section{Calculating Changes in Rural Population and Farmland}

The difference in household registration status between urban and rural areas is weakening [24]. Therefore, in order to accurately reflect the change process for the population-land relationship in rural 
areas, a change analysis of rural population was undertaken based on the number of rural permanent residents. The farmland quantity change was based on the farmland change analysis. Absolute change, relative change, annual change, and other total and ratio indicators are normally used to reflect the increasing and decreasing trends for quantity change. In addition, the long time span involved in this study and the differences in the number of years within each research period also had to be taken into consideration. Therefore, the annual average change rate for rural population (Population Annual Rate, PAR), the annual average change rate for farmland (Farmland Annual Rate, FAR) [33], and the average annual change rate per capita farmland of rural population (Per Capita Farmland Annual Rate, PCFAR) in a certain period were used to quantify the changes in rural population and farmland (Equations 1-3).

$$
\begin{gathered}
\text { PAR }_{i t}=\left(\sqrt[t]{\frac{P_{(1+t) i}}{P_{1 i}}}-1\right) \times 100 \% \\
\text { FAR }_{i t}=\left(\sqrt[t]{\frac{F_{(1+t) i}}{F_{1 i}}-1}\right) \times 100 \% \\
\text { PCFAR }_{i t}=\left(\sqrt[t]{\frac{P C F_{(1+t) i}}{P C F_{1 i}}}-1\right) \times 100 \%
\end{gathered}
$$

...where $P A R_{i t}$ and $F A R_{i t}$ respectively represent the annual average change rate for rural population and the annual average change rate for farmland in the year t of the i research unit; $P_{1 i}$ and $P_{(1+t) i}$ represent the rural population number in the $\mathrm{i}$ research unit at the beginning and end of the study, respectively; $F_{1 i}$ and $F_{(1+t) i}$ represent the amount of farmland in the $\mathrm{i}$ research unit at the beginning and end of the research, respectively; and $P C F_{1 i}$ and $P C F_{(1+t) i}$ represent the per capita farmland of rural population in the i research unit at the beginning and end of the study, respectively.

\section{Population-Farmland Elastic Coefficient (PFEC)}

The elastic coefficient is the ratio of the rates of change of two interrelated indicators over a given period. It is a measure of how dependent the change range of one indicator is on the change range of another indicator. This study used the elastic coefficient model of rural population and farmland changes to determine the spatio-temporal coupling characteristics of rural population and farmland changes by analyzing the direction and relative velocity of rural population and farmland area change. If the labour-farmland elasticity index [1] and the elastic coefficient of rural residential land [33] are used, then the population-farmland elastic coefficient (PFEC) can be defined as the ratio of the rate of rural population change to the rate of change of farmland extent rate over a certain period $[33,41]$ (Equation 4).

$$
\text { PFEC }_{i t}=\frac{P A R_{i t}}{F A R_{i t}}
$$

...where PFEC is the population-farmland elastic coefficient; PAR and FAR are defined as above.

\section{Coupling Relationship Types Between Rural Population and Farmland Change}

At the current level of agricultural productivity, accelerating the migration of the rural population and promoting large-scale land management can help increase farmland per capita, improve agricultural productivity, and help mitigate the tense populationland relationship in ecologically vulnerable areas. This type of change between a rural population and farmland is called a coordinated type. In contrast, there is also non-coordinated change.

The coupling relationship between rural population and farmland change can be classified into eight types

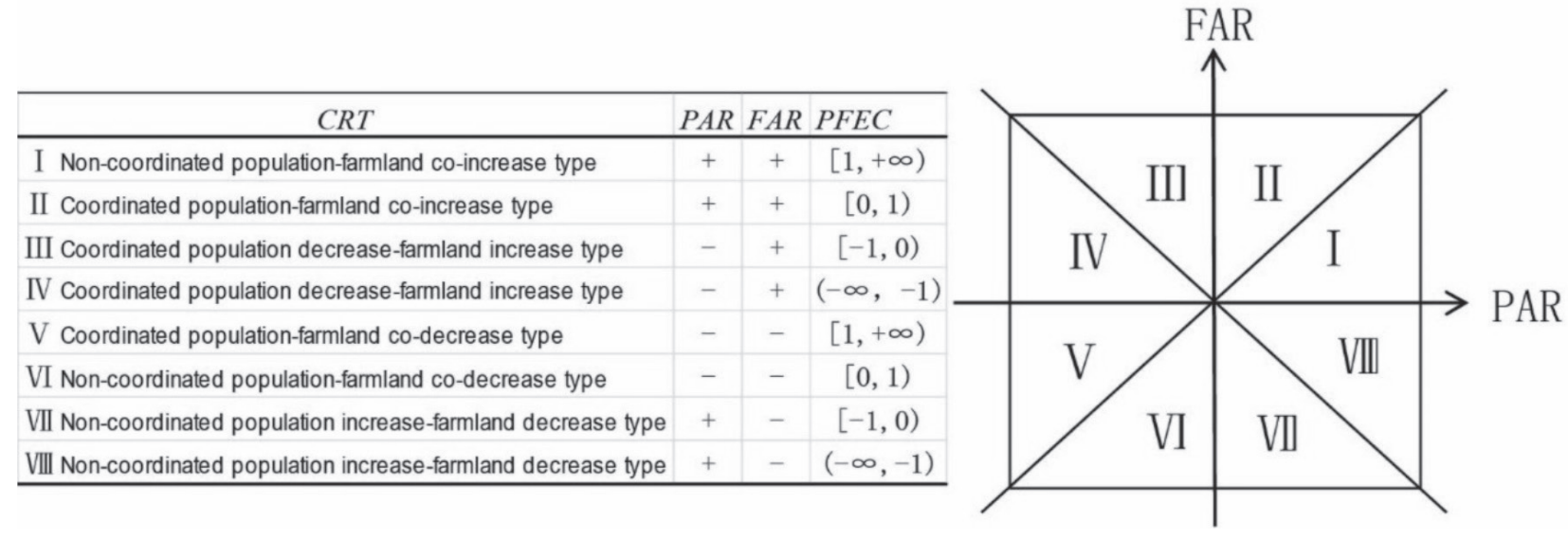

Fig. 2. Coupling relationship types between the rural population and farmland change. 


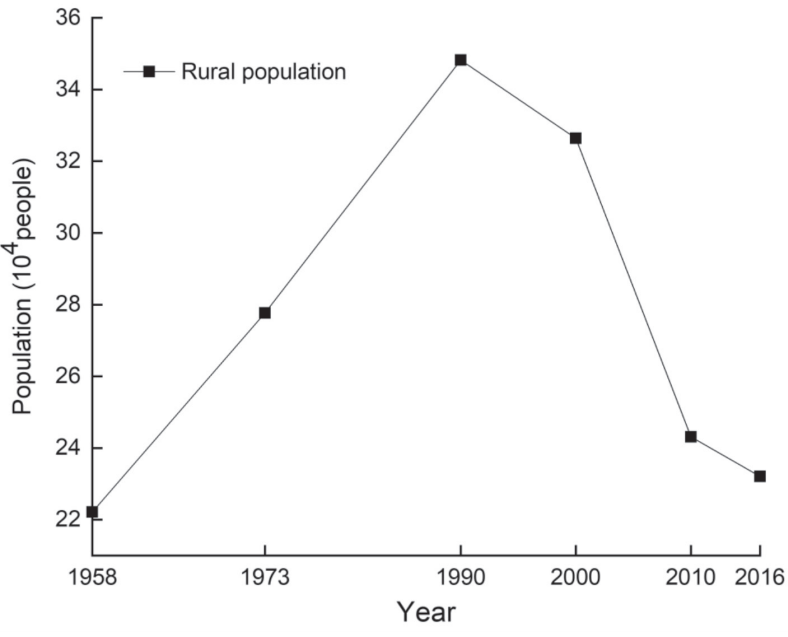

Fig. 3. Changes in rural populations across Yinjiang County from 1958 to 2016.

based on changes to PAR, FAR, PCFAR, and PFEC (Fig. 2). Among them, although VII and VIII are both non-coordinated, the absolute value of PAR is less than the absolute value of FAR in VII, and the absolute value of PAR is greater than the absolute value of FAR in VIII. The same is true for III and IV. For instance, if the PFEC value is within Zone I, PAR and FAR are both positive and PAR is greater than FAR, that is, the rural population and farmland are both growing, but the population growth rate is faster. Therefore, it is a non-coordinated area with reduced per capita farmland. If the PFEC value falls in zone IV, PAR decreases and FAR increases, and the rate of decrease in PAR is faster. Therefore, it is a coordinated area with an increase in per capita farmland.

\section{Results and Analysis}

\section{Temporal and Spatial Characteristics of Rural Population Changes}

From 1958 to 2016, the rural population in Yinjiang County grew rapidly, peaking in 1990 after which it then rapidly declined (Fig. 3). The spatial characteristics of the rural population changes had significant effects on nature and the social economy. The period from 1958-1990 was the growth stage with an average annual growth rate of $1.42 \%$ (i.e. 3100 people). From 1958 to 1973, the population of each village in the county rapidly increased. From 1973 to 1990, rapid growth still occurred with the most rapid growth areas a. $1958-1973$

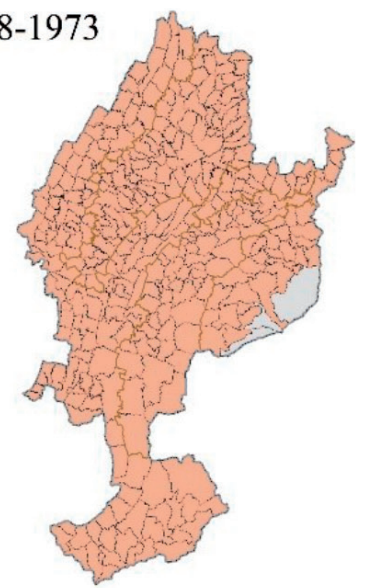

d. $2000-2010$

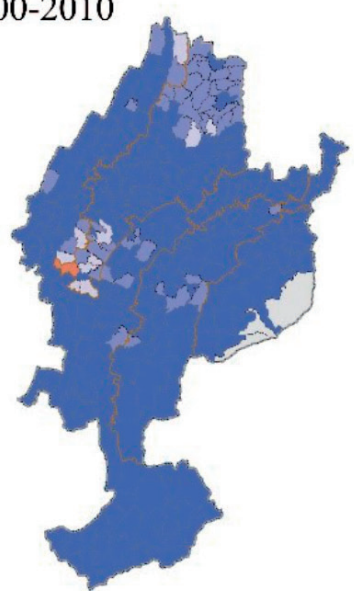

b. $1973-1990$

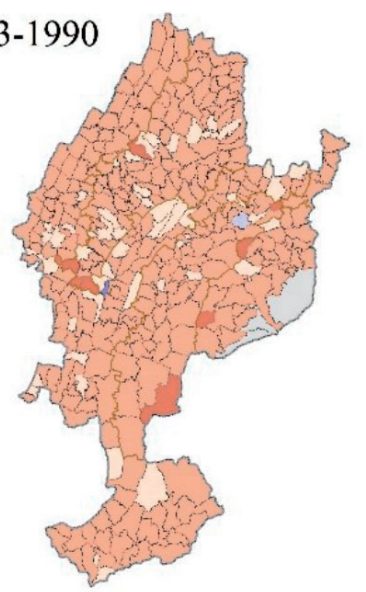

e. $2010-2016$

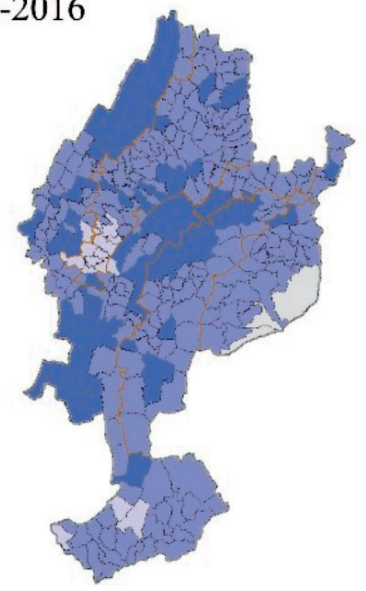

c. $1990-2000$

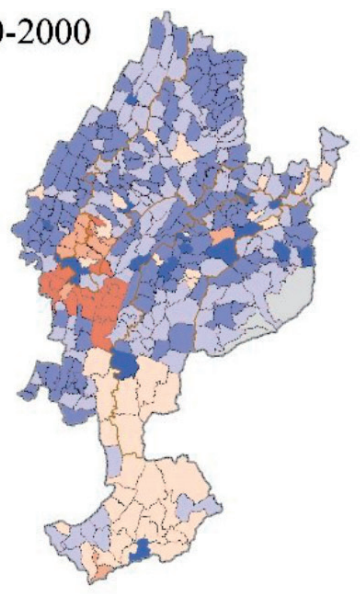

Population Annual Rate(\%)

The most rapid decline area $\leqslant-2$

Rapid decline area $(-2,-1]$

Slow decline area $\quad(-1,0]$

Slow growth area $(0,1]$

Rapid growth area $\quad(1,2]$

The most rapid growth area $>2$

No date

5 . $10 \mathrm{~km}$

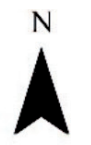

Fig. 4. Spatial and temporal patterns for rural population change in Yinjiang County from 1958 to 2016. 
mainly distributed in parts of the county towns and the villages where locally important governments were located such as Chanxi, Banxi, Muhuang, and Ziwei. The slow growth areas were distributed in strips across the trough valley area and the hilly valley area in the northwest and middle of the county (Fig. 4). Between 1990 and 2000, the population entered a period of slow decline, with an average annual decrease rate of $0.65 \%$ (i.e. 2200 people). The most rapid growth areas were mainly distributed in a planar pattern with the county town as the center whereas the slow growth areas were concentrated in the southern part of the trough valley area and the southern part of the low hill and river valley area. The population of the remaining areas also decreased. Rural population declined rapidly between 2000 and 2010 with an average annual decrease rate of $2.84 \%$ (i.e. 9200 people). Only the population of villages near the county towns increased. Populations in the northern and southern areas of the hilly valleys decreased slowly, while populations in the remaining regions declined rapidly (Fig. 4). Rural population fell rapidly between 2010 and 2016 with an average annual decrease rate of $2.24 \%$ (i.e. 8500 people).

\section{Spatio-Temporal Characteristics of the Farmland Changes}

From 1958 to 2016, the area of farmland in Yinjiang County grew rapidly at first, but entered into a slow decline (Fig. 5). Before 1990, the average annual farmland growth rate was $0.23 \%$ (i.e. $85.35 \mathrm{hm}^{2}$ ). From 1958 to 1973 , the rapid growth area was in the north of the trough valley area and the hilly valley area, whereas the slow growth areas were concentrated in the southern part of the trough valley area and the north-central part of the low hill and river valley area. The rapid decline areas were concentrated around the county towns, in the middle of the trough valley area, in the southern part of the low hill and river valley area, and in the medium height mountain area of Fanjing Mountain. From 1973 to 1990 , the most rapid growth areas were distributed in two bands across the trough valley area and in the low hill and river valley area. Slow decline areas were widely distributed across the county with rapid decline areas located in the southern part of the trough valley area and medium height mountain areas of Fanjing Mountain.

The 1990-2000 results showed that farmland growth was slow with an annual growth rate of $0.05 \%$ (i.e. $20.95 \mathrm{hm}^{2}$ ). The most rapid growth areas were distributed at the edge and in the southern part of the trough valley area, and in the southeast part of the low hill and river valley areas. The locations where farmland area was decreasing were distributed across all parts of the county. After 2000, the overall farmland area in the county demonstrated a decreasing trend. The period from 2000 to 2010 was a period of slow decrease with an average annual decrease of $0.14 \%$ (i.e. $57 \mathrm{hm}^{2}$ ). The growth areas were mainly concentrated in the

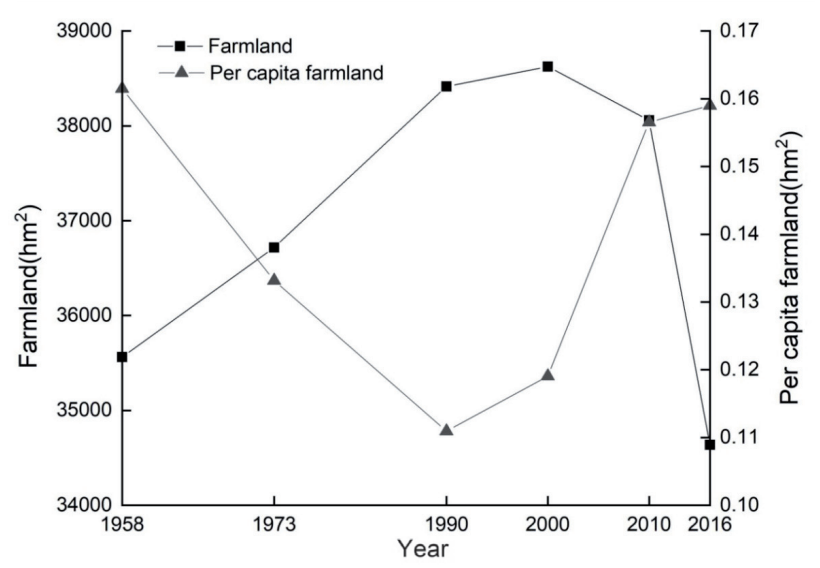

Fig. 5. Changes in farmland area and per capita rural farmland in Yinjiang between 1958 and 2016.

bottom area of the hilly valley and around the villages in the middle and eastern parts of the low hill and river valley area. Farmland area also decreased in the trough valley area and the medium height mountain area of Fanjing Mountain. However, the most rapid decline areas were mainly distributed around the villages in the center of the county. Farmland area rapidly decreased between 2010 and 2016 with an average annual decrease of $1.56 \%$ (i.e. $592.77 \mathrm{hm}^{2}$ ). The most rapid decline areas were mainly concentrated in the trough valley (Fig. 6).

\section{Temporal-Spatial Characteristics of per Capita Farmland Change}

The per capita farmland area in Yinjiang County decreased from $0.162 \mathrm{hm}^{2} /$ capita in 1958 to $0.112 \mathrm{hm}^{2} /$ capita in 1990 with an average annual decrease rate of $1.17 \%$. However, it increased after 1990. The growth rate was relatively large then from 2000 to 2016 with an average annual growth rate of $1.82 \%$ (Fig. 5). The per capita farmland area was $0.159 \mathrm{hm}^{2}$ capita in 2016. The most rapid growth areas from 1958 to 1973 were mainly distributed in the northern part of the trough valley area, the central and northern parts of the hilly valley area, and the central part of the low hill and river valley area, whereas the most rapid decline areas were mainly distributed in the central and southern trough valley area, the southern low hill and river valley area, and the medium height mountain areas of Fanjing Mountain. The per capita farmland area in the county generally decreased between 1973 and 1990, but it increased in some villages across the north of the trough valley area and the northeast part of the low hill and river valley area. From 1990 to 2000, farmland per capita in $69.7 \%$ of villages increased. The most rapid growth villages accounted for $21.7 \%$ of the total village number in the county and they were mainly distributed in the south, southwest, and northwest of the trough valley area, the northern part of the hilly valley area, and the central and northern parts of the low hill and river valley area. 

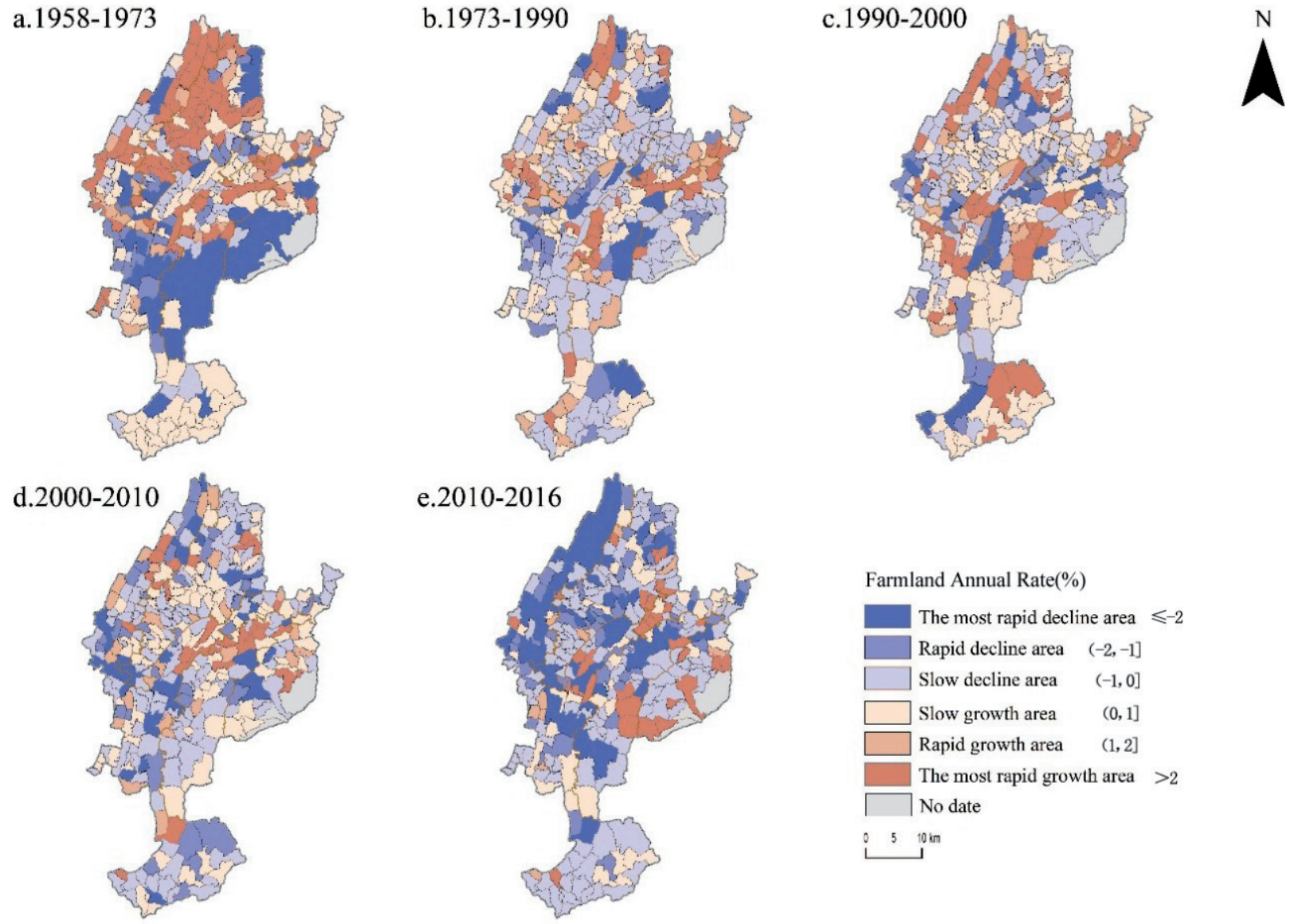

Fig. 6. Spatial patterns for farmland change in Yinjiang County from 1958 to 2016.

Only $12.6 \%$ of the villages showed a rapid decrease in per capita farmland area and these were mainly distributed in the central part of the county and in the trough valley area. From 2000 to 2016, per capita farmland area in $89.9 \%$ of villages increased. The most rapid growth villages were widely distributed and accounted for $55.3 \%$ of the total village number. Only $5.48 \%$ of the villages were defined as being most rapid decline areas and were sporadically distributed around where the market town was located and in the northeast part of the trough valley area (Fig. 7).

\section{Spatial-Temporal Coupling Relationships between Rural Population and Farmland Change}

\section{Spatio-Temporal Coupling Characteristics of the Rural Population and Farmland Change Relationships}

From 1958 to 2016, the coupling relationship between rural population and farmland change across the time series in Yinjiang County changed from a noncoordinated population-farmland change relationship to a coordinated population-farmland change relationship. Non-coordinated types of population-farmland dominated during the periods 1958-1973 and 1973-1990, whereas coordinated types of population decreasefarmland increase dominated from 1990-2000, and a coordinated population decrease-farmland decrease relationship dominated from 2000-2016.

The spatio-temporal coupling types for rural population and farmland change are shown in Table 1 and Fig. 8. From 1958 to 1973 , the types were mainly composed of villages with non-coordinated populationfarmland changes. They accounted for $68.37 \%$ of the total number of villages in the county, with the numbers of different non-coordinated types from high to low being Type I>Type VII>Type VIII. Type I was mainly concentrated in the villages across the south and marginal parts of the trough valley area and the northeast part of the low hill and river valley area. Type VII villages were distributed around the county town and the villages where locally important governments were located such as Tangxi, Muhuang, and Ziwei. Type VIII villages were mainly concentrated in the west and middle of the trough valley area, the middle and south of the low hill and river valley area, and the medium height mountain areas of Fanjing Mountain. Villages with coordinated population-farmland change only showed Type II characteristics and accounted for $30.49 \%$ of the total village number in the county. They were mainly distributed in the central and northern parts of the hill valley area. Between 1973 and 1990, the area was still dominated by non-coordinated population-farmland change villages and the number 

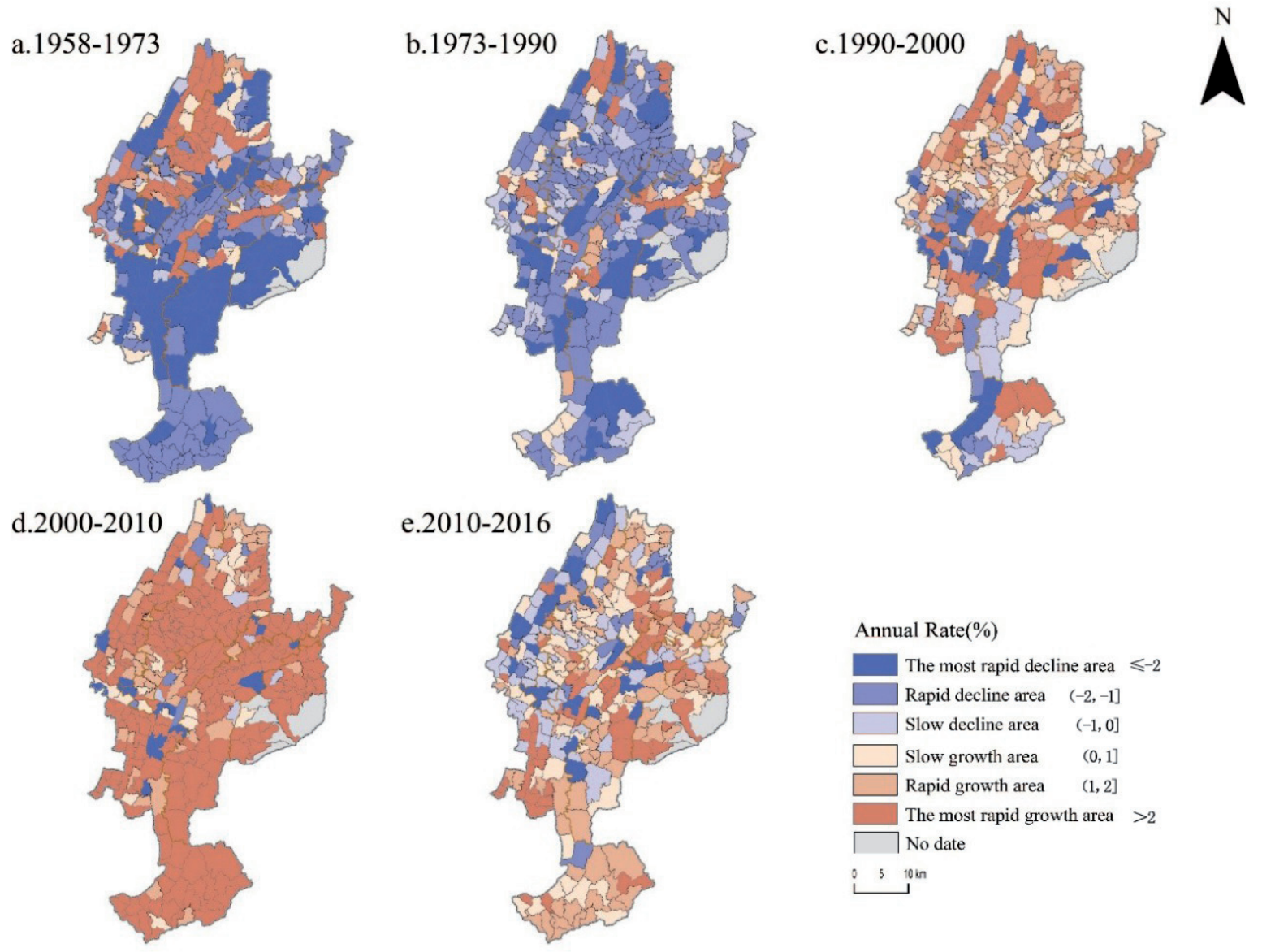

Fig. 7. Spatial patterns for per capita rural farmland change in Yinjiang County from 1958 to 2016.

of villages had increased to $80.05 \%$ of the total villages in the county, with the numbers from high to low being Type VIII $>$ Type I $>$ Type VII $>$ Type VI. Type VIII had the highest growth rate with an increase of 2.67 times compared to $1958-1973$ and these areas were distributed across the county. However, the coordinated type of population-farmland change was still dominated by Type II, although the number of villages in this type decreased to $18.81 \%$ compared to $1958-1973$. They were mainly distributed in a strip shape across the northwest of the trough valley area and the middle and east of the low hill and river valley area. From 1990 to 2000, the county mainly consisted of villages that showed coordinated population-farmland change, and all four coordinated types accounted for $68.67 \%$ of the total villages. The number of different coordinated villages was in the order of Type V>Type IV>Type III $>$ Type II. Type $\mathrm{V}$ was mainly located in areas other than the south; Type IV was mainly distributed in the central and southern trough valley area, the hill valley area, and the medium height mountain areas of Fanjing Mountain; and Type III was mainly distributed in the central and northwest rough valley area and the central part of the low hill and river valley area. During this period, the number of non-coordinated villages decreased to $30.19 \%$ of the total number of villages. All four non-coordinated types were observed. The largest number of villages were classified as Type VI and these were mainly distributed in the southern part of the trough valley area and the central parts of the low hill and river valley area. From 2000 to 2010, 90.89\% of the villages in the county had coordinated type classifications. The number of different coordinated villages was in the order Type V>Type IV>Type III. Type II was distributed throughout the county whereas Type V was mainly distributed in the middle of the hill valley area, the low hill and river valley area and the medium height mountain areas of Fanjing Mountain. The non-coordinated type villages i.e. Type VI accounted for only $7.97 \%$ of the county villages and mainly composed of individual villages around county towns and important market towns. From 2010 to 2016, $89.74 \%$ of the total number of villages in the county had coordinated type classifications. The distribution type was similar to that of the previous period (Table 1) (Fig. 8).

\section{Comparison of the Spatio-Temporal Coupling Relationships between Rural Population and Farmland Changes in the Trough Valley and the Non-Trough Valley Areas}

The trend in temporal coupling between rural population and farmland changes in the trough and 
Table 1. Coupling relationship types between rural population and farmland change in Yinjiang County from 1958 to 2016.

\begin{tabular}{|c|c|c|c|c|c|c|}
\hline \multirow{2}{*}{\multicolumn{2}{|c|}{ Coupling relationship between rural population and farmland change }} & \multicolumn{5}{|c|}{ Village } \\
\hline & & \multirow{2}{*}{$\frac{1958-1973}{107}$} & \multirow{2}{*}{$\frac{1973-1990}{65}$} & \multirow{2}{*}{$\frac{1990-2000}{15}$} & \multirow{2}{*}{$\frac{2000-2010}{0}$} & \multirow{2}{*}{$\frac{2010-2016}{0}$} \\
\hline \multirow{5}{*}{ Coordinated } & Coordinated population-farmland co-increase type (II) & & & & & \\
\hline & $\begin{array}{l}\text { Coordinated population decrease-farmland increase } \\
\text { type (III) }\end{array}$ & 0 & 1 & 59 & 23 & 34 \\
\hline & $\begin{array}{l}\text { Coordinated population decrease-farmland increase } \\
\text { type (IV) }\end{array}$ & 0 & 0 & 74 & 130 & 47 \\
\hline & Coordinated population-farmland co-decrease type $(\mathrm{V})$ & 0 & 0 & 93 & 166 & 234 \\
\hline & Total & 107 & 66 & 241 & 319 & 315 \\
\hline \multirow{5}{*}{$\begin{array}{l}\text { Non } \\
\text {-coordinated }\end{array}$} & $\begin{array}{l}\text { Non-coordinated population-farmland } \\
\text { co-increase type (I) }\end{array}$ & 103 & 82 & 27 & 0 & 0 \\
\hline & $\begin{array}{l}\text { Non-coordinated population-farmland } \\
\text { co-decrease type (VI) }\end{array}$ & 0 & 1 & 54 & 28 & 32 \\
\hline & $\begin{array}{l}\text { Non-coordinated population increase-farmland } \\
\text { decrease type (VII) }\end{array}$ & 76 & 36 & 11 & 0 & 0 \\
\hline & $\begin{array}{l}\text { Non-coordinated population increase-farmland } \\
\text { decrease type (VIII) }\end{array}$ & 61 & 162 & 14 & 0 & 0 \\
\hline & Total & 240 & 281 & 106 & 28 & 32 \\
\hline \multicolumn{2}{|r|}{ No date } & 4 & 4 & 4 & 4 & 4 \\
\hline
\end{tabular}

a.1958-1973

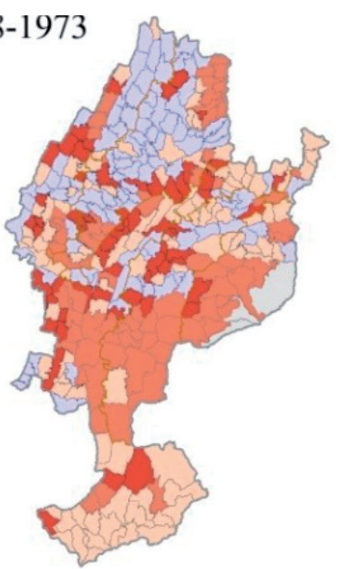

d. $2000-2010$

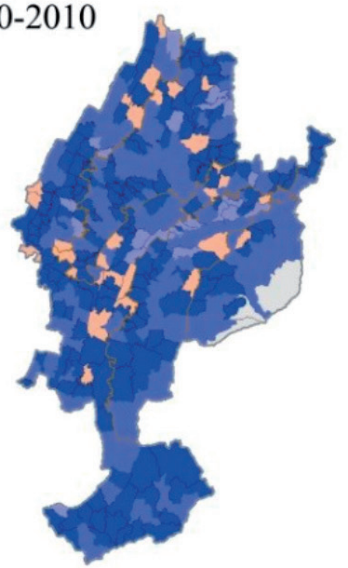

b. $1973-1990$

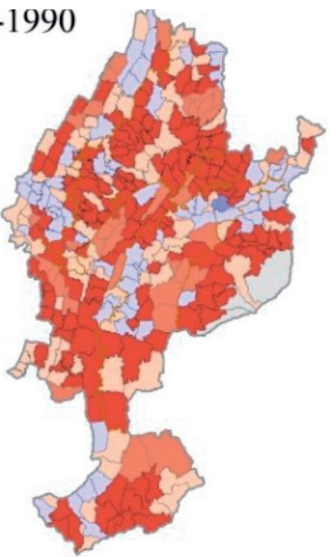

e.2010-2016

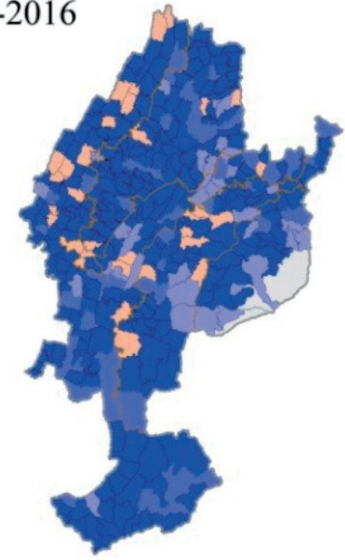

c. $1990-2000$

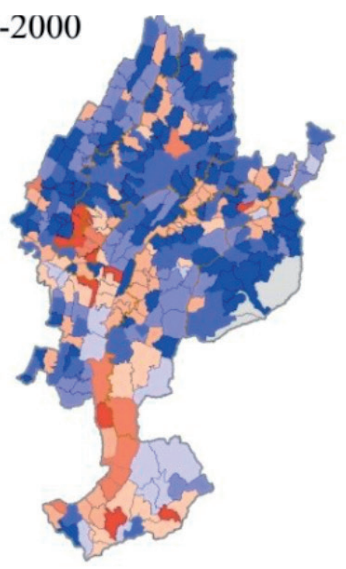

$\mathrm{N}$

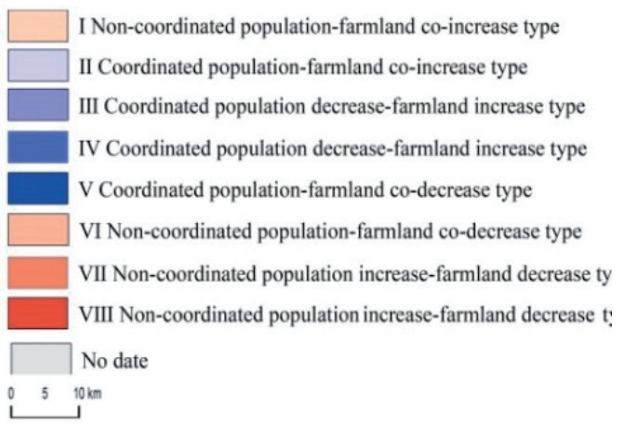

Fig. 8. Coupling types for rural population and farmland change in Yinjiang County from 1958 to 2016. 
non-trough valley villages was basically the same from 1958 to 2016, with the coupling relationships between rural population and farmland changes shifting from non-coordinated to coordinated. In addition, the proportion of each coupling type significantly changed. For the periods 1958-1973, 1990-2000, 20002010, and 2010-2016, the percentage of villages with non-coordinated classifications in the trough valley area was higher than in the non-trough area while the proportion of coordinated types was the opposite (Fig. 9(a-b)). For example, the proportion of noncoordinated villages in the trough area was $11.04 \%$, whereas it was $5.43 \%$ the non-trough area between 2000 and 2010. In terms of spatial distribution, both trough and non-trough valley areas were further divided into dam villages and hillside villages. From 1958 to 2016,

\section{a.Trough valley area}

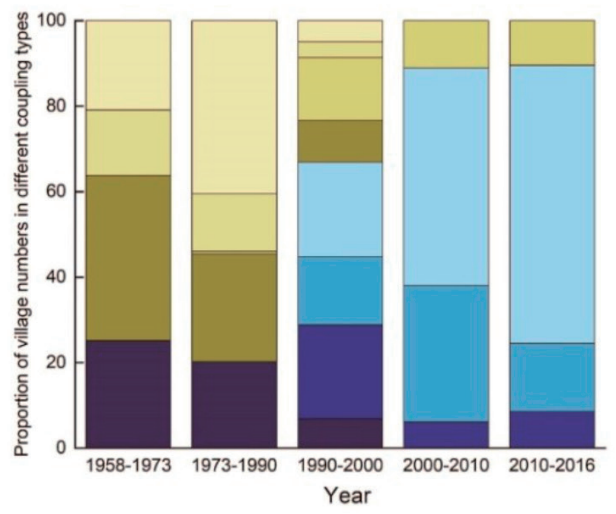

c.Dam village in trough valley area

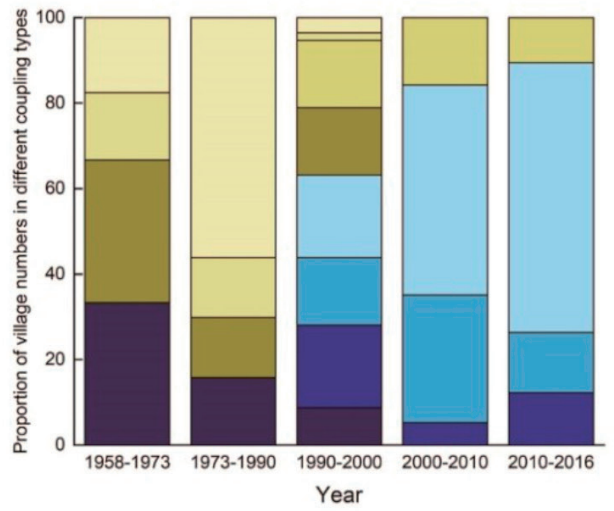

e.Hillside village in trough valley area

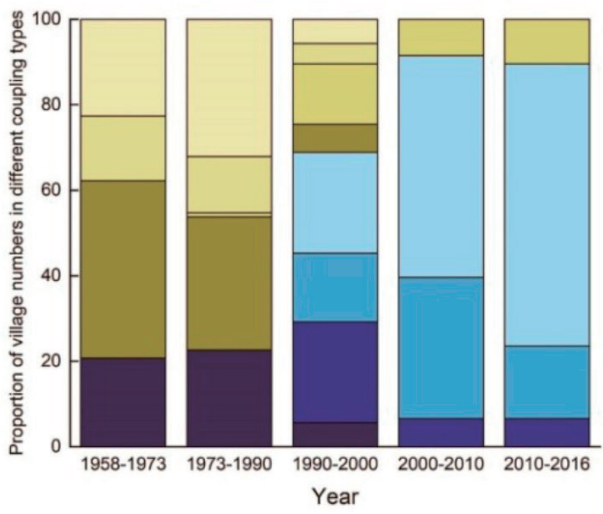

I Non-coordinated population-farmland co-increase type VI Non-coordinated population-farmland co-decrease type VII Non-coordinated population increase-farmland decrease type VIII Non-coordinated population increase-farmland decrease type

\section{b.Non-trough valley area}

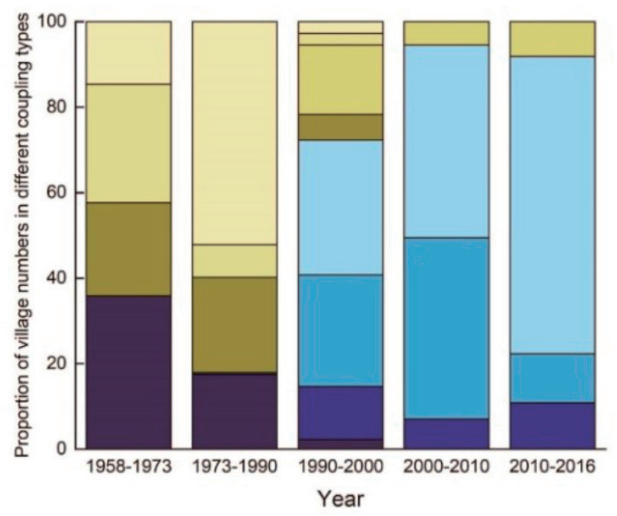

d.Dam village in non-trough valley area

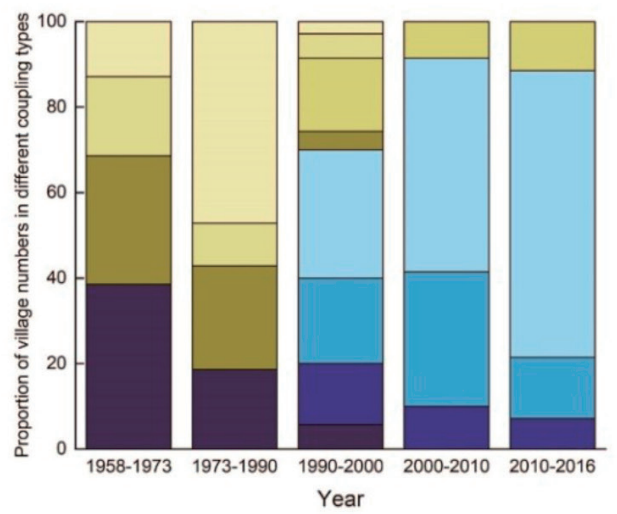

f.Hillside village in non-trough valley area

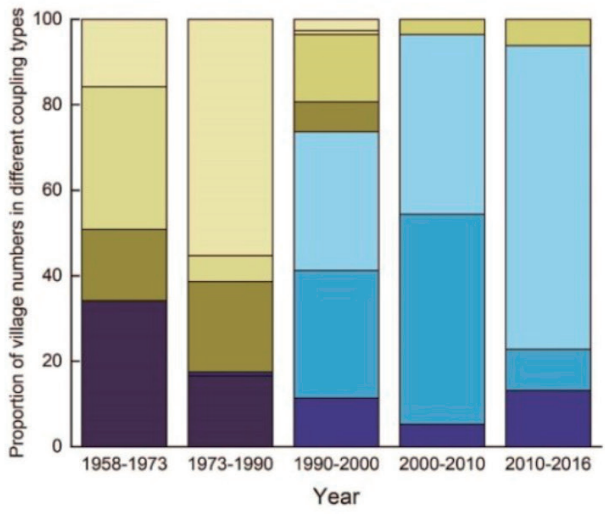

II Coordinated population-farmland co-increase type

III Coordinated population decrease-farmland increase type

IV Coordinated population decrease-farmland increase type

V Coordinated population-farmland co-decrease type

Fig. 9. Proportion of villages in the different coupling type classifications for farmland and rural population changes in the Trough Valley region and other karst area regions in Yinjiang County between 1958 and 2016. 
the percentage of non-coordinated dam villages in the trough valley area was higher than the percentage of non-coordinated dam villages in the non-trough valley area, while the proportion of coordinated type villages was the opposite for the two areas (Fig. 9(c-d)). The hillside and dam village trends were consistent in the trough valley and non-trough valley areas (Fig. 9(e-f)). This suggested that the degree of population-farmland change coordination in the trough valley area was lower than in the non-trough valley area.

\section{Comparison of Temporal-Spatial Coupling Types between Rural Population and Farmland Changes in Dam Villages and Hillside Villages Across the Trough Valley Area}

The coupling trend between rural population and farmland changes in dam and hillside villages across the trough valley area was consistent but with different proportions for each coupling type (Fig. 9(c,e)). Except for the period 1958-1973, the proportion of noncoordinated dam villages was higher than that for hillside villages in the trough valley area, whereas the opposite was true for the coordinated village types. For instance, from 2000-2010, the percentage of coordinated villages increased to $84.21 \%$ and $91.51 \%$ among the dam villages and hillside villages in the trough valley area, respectively, which suggested that population-farmland change coordination in hillside villages was better than in dam villages within the trough valley area and that it had improved over time.

\section{Discussion}

Transformation of the Coupling Relationship between Rural Population and Farmland Changes

The coupling relationship between rural population and farmland changes has been transformed for the karst region of Southwest China. In traditional agricultural societies, the rural population relies solely on land resources. However, since China implemented the "Reform and Opening Up" policy in 1978, the rural population has extensively and continuously migrated to urban areas. China has been transformed from a traditional agricultural society dependent on land to an open, modern, industrial, and urban society, which has led to changes in the coupling relationship between the rural population and farmland change. This has been shown by many studies across China $[16,33,42]$ that have investigated areas such as the middle sections of the Yangtze River, the Huang-Huai-Hai area, the Pearl River Delta [43] and the Three Gorges Reservoir area [44]. The current study selected Yinjiang County in the Karst trough valley area of Southwestern China as its research area. The Karst area of Southwest China has undergone the same economic and social development changes as the rest of China. Based on a comprehensive analysis of indicators such as change rate for farmland, change rate for rural population, the population-farmland elastic coefficient, and per capita farmland of the rural population, this study has shown that the overall trend for rural population and farmland change is consistent with the nationwide trend [26]. The coupling relationship between rural population and farmland change in Yinjiang County has also undergone transformation. In Yinjiang County, the evolution of the coupling relationship between rural population and farmland change can be classified into a traditional agricultural period (1958-1990), a transition period (1990-2000), and an intensive agriculture period (2000-2016), and these periods, to a certain extent, reflect the general characteristics of the coupling relationship between rural population and farmland change in Southwest China. If the county is considered as a research unit, then the coupling relationship between rural population and farmland change in Yinjiang County changed from non-coordinated types of population-farmland co-increase between 1958 and 1990 to coordinated types of change, populationdecrease and farmland-increase between 1990 and 2000. It then changed to coordinated population-farmland codecrease during 2000-2016. Taking the village as the research unit, non-coordinated coupling first increased but then decreased (Fig. 10), whereas coordinated coupling first decreased but then increased (Fig. 10). This study found that the 1973-1990 period was the inflection point for both transitions. From 1990 to 2000, the coupling relationship between rural population and farmland change showed a diversified coexistence pattern for all eight coupling modes, which indicated that the coupling relationship between rural population and farmland change was the most complex at this stage. The coupling relationship between rural population and farmland change was mainly coordinated after 2000.

The results for landform zoning in Yinjiang County suggested that the trough valley areas and non-trough valley areas, and the trough dam and hillside villages within these areas had also undergone a transformation. The coupling relationship between rural population and farmland change in these sub-regions was most complex between 1990 and 2000 but became primarily coordinated after 2000

Future coupling relationship transformations between rural population and farmland change in Southwest China will still occur. China is still undergoing rapid urbanization, especially in the large southwestern regions of the country. Previous studies have projected that the urbanization rate would reach about $75 \%$ by 2050 and stabilize thereafter [25]. This suggested rural migration to cities and towns will continue to be a major trend in the coming decades and the urban population will remain stable rather than show unlimited growth. The "National Macro Farmland Protection Policy" and the "Ecological Environment Policy" have restrained the rapid decline 


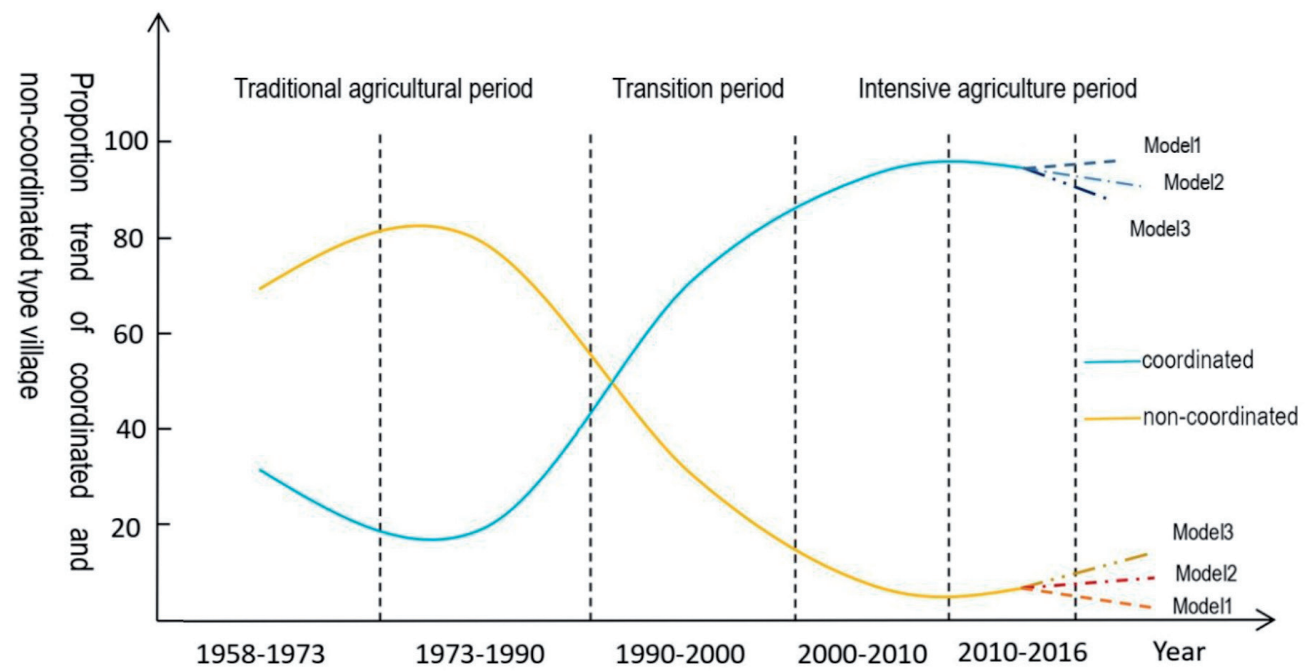

Fig. 10. Proportional trends for villages showing coordinated and non-coordinated rural population and farmland change.

in farmland across Southwest China with a certain proportion of farmland being maintained. The trends in rural population and farmland extent in Southwest China suggests that the area has entered a period of intensive agriculture. In the future, the rate of rural population decrease is expected to be greater than the rate of farmland change. The coupling relationship will be dominated by the coordinated types and will trend toward a stable ratio, while the non-coordinated types will account for a smaller proportion of the villages over time. these will evolve the second model2 (Fig. 10).

\section{Factors Driving the Coupling Relationship between Rural Population and Farmland Changes}

Based on change in the rural population and land usage, as well as the changes of the population-land coupling, combined with field investigations, this study is divided into traditional agriculture period, transition period and intensive agriculture period (Fig. 11).

Fig. 11 shows that the period 1958-1990 was generally a traditional agricultural stage. The establishment of the People's Commune and the promulgation of the "Regulations of the People's Republic of China on Household Registration" in 1958 meant that China entered a period in which the dual structure of the urban-rural division system was solidified. The rural population was confined to rural areas and engaged in solely agricultural livelihoods. The population development of Yinjiang County became chaotic, especially as the average annual increase was as high as $30.22 \%$ from 1968 to 1976 due to the increasing willingness of people to give birth after the founding of new China and the three-year Great Chinese Famine [45]. The household registration restrictions and the disordered population growth have caused a sharp rise in the demand for food. Farmers reclaimed large areas of arable land in mountainous areas to resolve food shortages. In the 1960s, floods frequently occurred in
Yinjiang County and sloping farmland was severely damaged, which drove further reclamation of additional sloped farmland. A Government Work Report in 1979 promoted the reclaiming of non-farmland and the division of self-retaining land to increase the land available for food production. It directly encouraged the deforestation of hills and the expansion of farmland into high altitude and steeply sloped areas. This stage caused a rapid growth in the rural population and a large expansion in farmland.

Based on change in the rural population and land usage, as well as the changes of the population-land coupling, combined with field investigations, this study is divided into traditional agriculture period, transition period and intensive agriculture period.

In the transition period from 1990 to 2000 , the region suffered from severe soil erosion leading to the implementation of a "Hillside-to-Terrace" project across Yinjiang County in 1991 to protect the reclaimed farmlands. However, as the economy developed in Yinjiang County, economic activities, such as industrial parks and economic development zones, began replacing farmland in the dam area, thereby slowing down the expansion of farmland. In the 1980s, national policies such as the "Household Responsibility System" and the "Notice of the State Council on Peasants Entering and Settling down in Towns" were implemented and these promoted agricultural production efficiency and the migration of rural populations to urban areas. Farmers also started part-time livelihood activities instead of solely relying on agricultural production for their income.

In the intensive agriculture stage from 2000 to 2016, the implementation of the "Western Development Policy" in 1999 meant that the economy output of Yinjiang County increased while farmer dependence on land gradually decreased [46], which alleviated the pressure on farmland for food production. National policy began to tilt towards ecological 


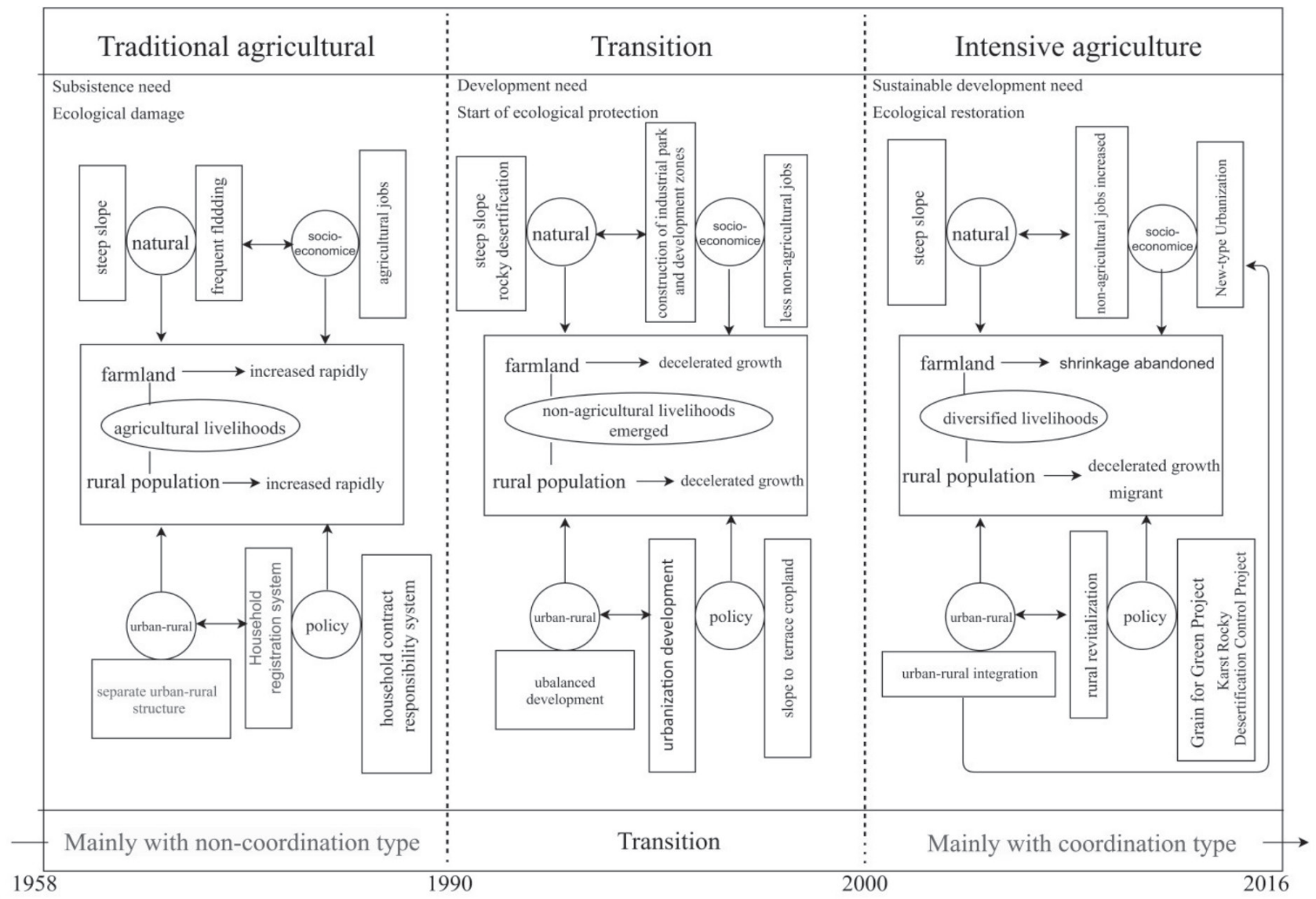

Fig. 11. Factors driving the coupling relationship between rural population and farmland change.

restoration after 2000. Yinjiang County also began to implement pilot work associated with the "Grain to Green Program". In 2000, it was selected as a pilot county for the comprehensive management of rock desertification in the Karst area of Guizhou Province, which gradually led to the shrinkage of farms on steep slopes. In 2005, Guizhou Province was exempted from agricultural taxes and started to receive food subsidies. The implementation of these policies transformed agriculture into large-scale, intensified production, but led to a decrease in the extent of farmland on steep slopes due to an increase in ecological restoration projects. In addition, labour costs rose and at the same time local primary industry labour gradually decreased. Rural depopulation continued and the livelihoods of rural households shifted to an agricultural livelihood supplemented by part-time work in other industries. In 2010, the Guizhou Province strategy of strengthening the province by industrialization and urbanization led to the expansion of urban construction land, while the high-altitude and steep slope farmland areas decreased. Rapid declines in the rural population, farmland shrinkage, and the abandonment of sloped land occurred during this period. Since 2014, Guizhou Province has implemented a targeted poverty alleviation strategy. In 2016, Yinjiang County was listed as a national key ecological function zone. Ecological migration and emigration meant that a large proportion of the rural population moved away. Remote farmland was abandoned and turned into forest-irrigated land whereas in comparison the concentrated and contiguous fruit land areas increased.

Through the analysis of the three stages of population and farmland changes in the study area, it can be concluded that the four driving factors affecting the coupled changes of population and farmland are mainly: natural environment, socio-economic conditions, policy, and changes in urban-rural relations (Fig. 12).

Natural environment is the original driving force along with topographical factors composed of slope and altitude that have obvious effects on the change of farmland in the Karst troughs. In the traditional agricultural society, when survival is the main purpose, human reclamation is first carried out in Karst valley areas and dam areas. When the farmland resources cannot meet the needs of human survival, farmers have to reclaim land on the steep slopes of the trough valley areas to meet demand. Excessive reclamation of steep slopes has led to the problem of rocky desertification in the Karst mountainous areas which has reduced the farmland and its quality. When the marginal income of the steep slope farmland decreases, the highest elevated land in the Karst trough area is the first to be abandoned. In addition, the rural population in highaltitude and steep slope areas tends to outflow more than the dam area. 


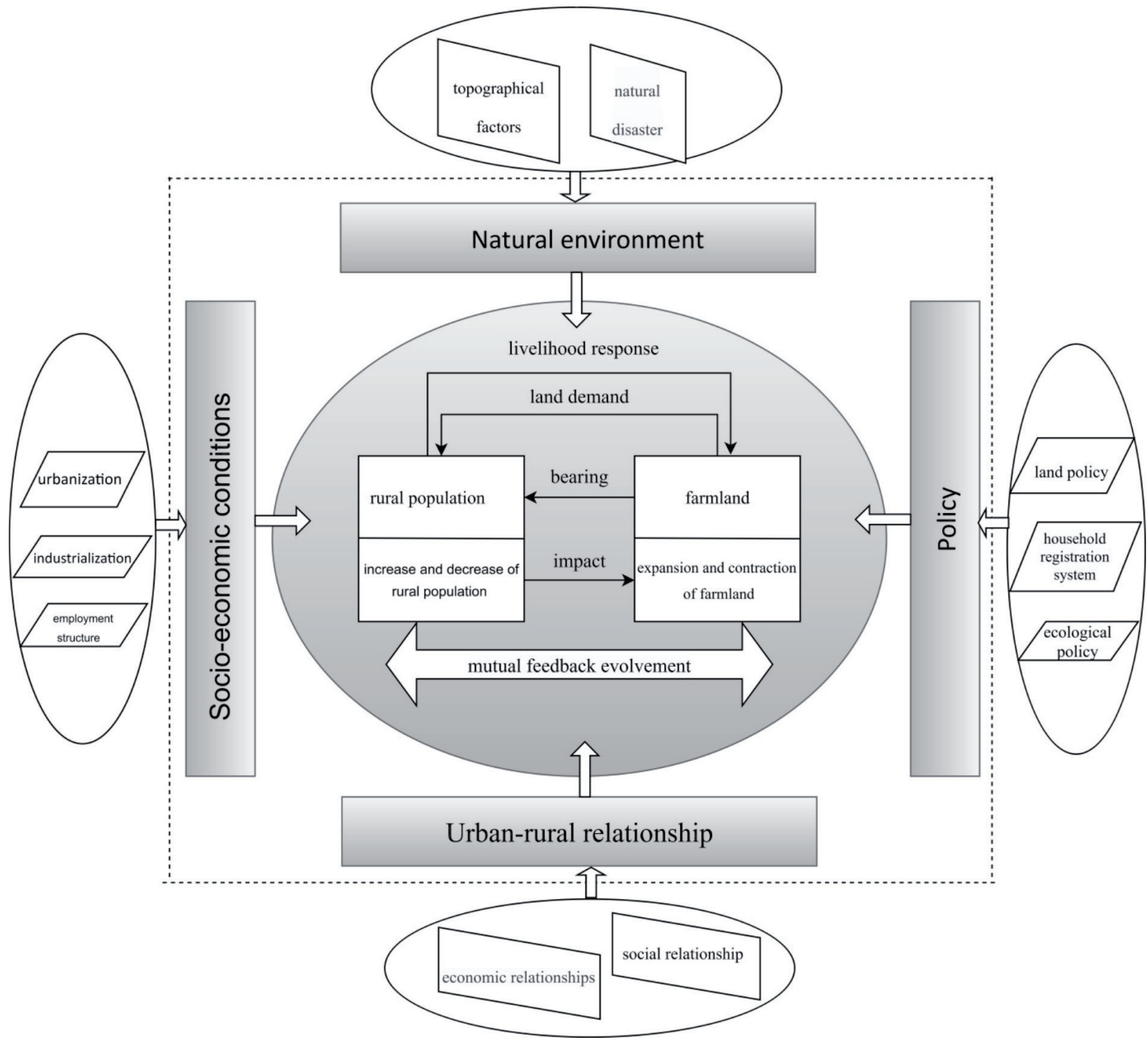

Fig. 12 Coupling factors that drive rural population and farmland change in Southwest China.

Socio-economic conditions are the basic driving force. With the development of the economy and continued industrial development, the employment opportunities provided have increased. Farmers do not only rely on agricultural activities that use land to produce income, but now gradually participate in more industrial activities, such as entering the construction and catering services. The progress of urbanization and industrialization will inevitably lead to the shrinkage of farmland and the migration of the rural population. The change from solely agricultural activities to industrial activities undertaken by farmers has caused changes in both population and land use. Farmers have gone from only working in agriculture, to now working part-time, and then onto the integrated development of primary, secondary and tertiary industries. Changes in the industrial activities that farmers engage in affects the degree of farmers' dependence on land, and so causes changes in the area of farmland cultivated.

Policy is the driving force behind the change. The top-down regional policy affects the rural population and farmland. The tightening and loosening of China's household registration system policy has caused the flow of the rural population in the urban and rural areas to go from 'no flow' to 'free flow'. The free movement of population is the most important driving factor for rural population change. The most influential land policies include the household responsibility contracting system, land improvement, and land transfer. In Karst trough areas the implementation of ecological protection and compensation policies such as returning farmland to forests and stony desertification control has made the use of steep slope farmland less attractive. As a result farmers' disturbance to the fragile environment is also lessening.

The change in the relationship between urban and rural areas is an external driving force [47] Since the founding of the People's Republic of China, the country's urban-rural relationship has developed from urban-rural antagonism to urban-rural integration. This has also promoted the flow of land and population factors between urban and rural areas [48]. The four 
factors previously mentioned act together on the population and farmland in the Karst trough area causing the interaction between the population and farmland. The interaction between population and farmland has transformed the livelihood of farmers from being purely agricultural based to now being more diversified.

Farmland is affected by the rural population demand for it and is an important resource for the rural population. Increases and decreases in the rural population affect the expansion and contraction of farmland use. Furthermore, the livelihood activities of the rural population also respond to farmland use.

\section{Inspiration of the Changes in Rural Population and Farmland, and their Coupling Relationship}

Although the region is only $1968.06 \mathrm{~km}^{2}$, the area covered by Karst landforms is extensive in the rural areas of Southwest China. The study region has undergone rapid social and economic development over the last six decades. Rural population growth, migration, and farmland-use have significantly changed. Its natural, social, and economic conditions are typical of rural areas in Southwest China. Therefore, the area can be used as a typical case study of Southwest China. The findings reflect the general coupling relationships between the rural population and farmland change, and the population-environment relationships in Southwest China. The results from this study provide a basis for optimizing the coupling relationship between rural population and farmland change.

\section{Ecological Significance}

The evolution of the coupling relationship between rural population and farmland change suggests that rural population migration is transforming Southwest China into a less land-dependent society [25]. Farmer livelihoods in Southwest China have undergone significant changes from total reliance on traditional agricultural production to part-time, non-agricultural production [26] which has alleviated the pressure on farmland resources and the environment in southwest mountainous areas where the population carrying capacity is small. The results also indirectly reflect that rocky desertification of Karst mountainous areas is also starting to reverse [49]. Previous research suggested that the migration of rural populations in Karst areas across Europe, South America, and the Caribbean reduced the degradation of fragile ecosystems, thereby promoting ecosystem restoration and improving the protection of watersheds and ecological diversity $[18,50$ 51]. The results from this current study are consistent with previous work in that the coupling relationship between rural population and farmland change tends to move from non-coordinated structures to more coordinated structures. Human disturbances that affect the occurrence of rocky desertification in southwest Karst areas have declined, which will positively affect the restoration of areas that have undergone rocky desertification.

\section{Rural Revitalization Recommendations}

The $19^{\text {th }}$ National Congress of the Communist Party of China [52] proposed that the implementation of a rural revitalization strategy is the general starting point and a long-term strategy for solving the issues concerning agriculture, the countryside, and farmers in China. In the context of the rural population outflow and the transformation of the coupling relationship between rural population and farmland change, the urban and rural development transformation laws should be followed to fully revitalize rural villages. However, the key to realizing the development goals for agricultural and rural modernization lies in how people manage farmland, especially those living in the countryside [53].

Based on the previous analysis, the four types of coupling of population and farmland in the karst valley area at the current stage are regulated in different regions. Category $\mathrm{V}$ areas, area is divided into two parts. In trough valley, strengthening ecological restoration on slopes, carrying out natural restoration on steep slopes, and developing ecological animal husbandry in high-altitude areas. In dam land and river valley areas, promoting the land transfer and realizing the appropriate scale of land operation. Category IV areas, In river valley areas, actively promoting land transfer, realizing the appropriate scale of land operation, and developing intensive agriculture. Reasonably fallowing in areas with steep slopes and developing efficient agriculture. In Category III, in river valley areas, actively promoting land transfer, realizing the appropriate scale of land operation, and developing high-efficiency agriculture. the VI area is strictly controlled in the surrounding areas of the county and suburban agriculture is developed.

In addition, in the context of rural population outflow, rural revitalization focuses on strengthening fixed asset investment in rural areas to promote the development of non-agricultural industries and provide farmers with local non-agricultural employment opportunities to increase income and reduce the gap between urban and rural areas. Through the development of rural education and culture, the talent support for sustainable rural development is strengthened.

In the future, it is necessary to fully explore the relationship between the rural population and the farmland after the outflow of the rural population, and then adopt targeted measures to promote the sustainable development of rural areas, and also provide good support for new urbanization. 


\section{Conclusions}

Using GIS technology and modeling methods, this study analyzed the changes in rural farmland area and population and their spatial-temporal coupling characteristics across mountainous Karst areas in Southwest China. The following conclusions can be drawn out:

(1) From 1958 to 2016, the rural population and farmland in mountainous Karst areas across Southwest China generally increased at first, but then decreased. In contrast, the per capita farmland area decreased at first and then increased. The rural population showed an increasing trend from 1958 to 1990, but slowly declined after 1990 and rapidly after 2000. Area of farmland experienced rapid growth from 1958 to 1990 , slow growth from 1990 to 2000 and rapid decline after 2000. The per capita farmland area of the rural population dropped from $0.162 \mathrm{hm}^{2} /$ person in 1958 to $0.112 \mathrm{hm}^{2} /$ person in 1990 , but then rose to $0.159 \mathrm{hm}^{2} /$ person in 2016 . The spatial variation of the rural population, farmland, and per capita farmland varied significantly from period to period.

(2) From 1958 to 2016, the spatio-temporal coupling relationships between the rural population and farmland in mountainous Karst areas across Southwest China have underwent a change process from unbalanced types to coordinated types. At the county scale, from 1958 to 1973 and from 1973 to 1990, Yinjiang County experienced non-coordinated types of population-farmland co-increase. After 1990, there was a shift. From 1990 to 2000, Yinjiang County experienced coordinated types of population decrease-farmland increase. Then, from 2000 to 2016, Yinjiang County experienced coordinated population-farmland co-decrease. At the village scale, before 1990, Karst trough valley area villages experienced the most varied disturbance types, mainly classes I and VIII. After 1990 the coordinate model showed that villages were mainly in classes IV and $\mathrm{V}$, and the relationship between people and land tended to be coordinated. In general, the number of coordinated villages in the non-trough region was higher than in the trough region. The spatio-temporal coupling relationships between the rural population and farmland is influenced by complex factors, especially the development of a social economy, population migration, and national policy changes, which generally mean that the coupling relationship evolves into a coordinated type.

(3) The spatial-temporal coupling relationships between the rural population and farmland change in mountainous Karst areas across Southwest China is affected by multiple factors. The factors driving the formation and development of the spatial-temporal coupling relationships between the rural population and farmland change are mainly associated with the combined effects of natural environment, socioeconomic conditions, policy, and changes in urban- rural relations. The results revealed that there were significant changes in the spatial-temporal coupling relationship between rural population and farmland in mountainous Karst areas across Southwest China over the past 60 years. The population-land relationship in rural areas has transitioned over the past few decades. Furthermore, continued rural population migration and the transformation of farmland mean that it is highly likely that ecological restoration, farmland planning and land resource distribution will follow similar trends in the future across mountainous Karst areas in Southwest China. This should lead to rural revitalization and a more harmonious population-land relationship.

\section{Acknowledgments}

This work was supported by grants from the National Key R\&D Program of China [No. 2016YFC0502300], the National Natural Science Foundation of China [No. 41661020 and 42061035], Project of Guizhou Province Science and Technology Department (No.Qian Kehe SZ $\mathrm{Zi}$ [2012] 3018); and the Humanities and Social Sciences Funds of Education Department of Guizhou Province (No. 2020QN007).

\section{Conflicts of Interest}

The authors declare no conflict of interest.

\section{References}

1. RICARDO GRAU H., MITCHELL AIDE T., ZIMMERMAN J.K., THOMLINSON J.R., HELMER E., ZOU X. The ecological consequences of socioeconomic and land-use changes in post-agriculture Puerto Rico. BioScience, 52, 1159, 2003

2. ZHANG B.L., SUN P.L., JIANG G. H., ZHANG R.J., GAO J.B. Rural land use transition of mountainous areas and policy implications for land consolidation in China. J. Geogr. Sci., 29, 1713, 2019.

3. SU K.C., YANG Q.Y., ZHANG B.L., ZHANG Z.X. The coupling mechanism between rural land use transition and small-scale peasant economy change in mountainous areas. Geogr. Res., 38, 399, 2019.

4. LAMBIN E.F., BAULIES X., BOCKSTAEL N., FISCHER G., KRUG T., LEEMANS R., MORAN E.F., RINDFUSS R.R., SATO Y., SKOLE D., TURNER B.L. II, VOGEL C. Land-use and land-cover change (LUCC): implementation strategy. IGBP Report 48, IHDP Report 10, International Geosphere-Biosphere Programme, International Human Dimensions on Global Environmental Change Programme, Stockholm Bonn, 125, 1999.

5. GEIST H.J., LAMBIN E.F. Dynamic causal patterns of desertification. BioScience, 54, 817, 2004.

6. LAMBIN E.F., GEIST H.J. Land-use and land-cover change local processes and global impacts. Springer, 2006.

7. LIU Y.S., LI Y.H. Revitalize the world's countryside. Nature, 548, 275, 2017. 
8. LI Y.H., WESTLUND H., LIU Y.S. Why some rural areas decline while some others not: an overview of rural evolution in the world. J Rural Stud., 68, 135, 2019.

9. CHEN R.S., YE C., CAI Y.L., XING X.S., CHEN Q. The impact of rural out-migration on land use transition in China: Past, present and trend. Land Use Policy, 40, 101, 2014.

10. LI Y.H., WESTLUND H., CARS G. Future urban-rural relationship in China: comparison in a global context. China Agric. Econ. Rev., 2, 396, 2010.

11. LONG H.L., LIU Y.S. Rural restructuring in China. J. Rural Stud., 47, 387, 2016.

12. ZHANG G.P., LIU J.Y., ZHANG Z.X. Spatial-temporal changes of cropland in China for the past 10 years based on remote sensing. Acta Geogr. Sin., 58, 323, 2003.

13. LI Y.H., LI Y.R., WESTLUND H., LIU Y.S. Urban-rural transformation in relation to cultivated land conversion in China: implications for optimizing land use and balanced regional development. Land Use Policy., 47, 218, 2015.

14. LONG H.L., GE D.Z., ZHANG Y.N., TU S.S., QU Y., MA L. Changing man-land interrelations in China's farming area under urbanization and its implications for food security. J. Environ. Manage., 209, 440, 2018.

15. GE D.Z., LONG H.L., ZHANG Y.N., TU S.S. Analysis of the coupled relationship between grain yields and agricultural labor changes in China. J. Geogr. Sci., 28, 93, 2018.

16. GE D.Z., LONG H.L, ZHANG Y.N., MA L., LI T.T. Farmland transition and its influences on grain production in China. Land Use Policy., 70, 94, 2018.

17. LI S.F., LI X.B. The mechanism of farmland marginalization in Chinese mountainous areas: evidence from cost and return changes. J. Geograph. Sci., 29, 531, 2019.

18. MACDONALD D., CRABTREE J.R., WIESINGER G., DAX T., STAMOU N., FLEURY P., GTIERREZ LAZPITA J., GIBON A. Agricultural abandonment in mountain areas of Europe: environmental consequences and policy response. J. Environ. Manage., 59, 47, 2000.

19. WANG S.J., LIU Q.M., ZHANG D.F. Karst rocky desertification in southwestern China: geomorphology, landuse, impact and rehabilitation. Land Degrad. Dev., 15, 115, 2004.

20. CAO J.H., YUAN D.X., TONG L.Q., MALLIK A., YANG H., HUANG F. An overview of karst ecosystem in southwest China: current state and future management. J. Resour. Ecol., 6, 247, 2015.

21. JIANG Z.C., LIAN Y.Q., QIN X.Q. Rocky desertification in Southwest China: impacts, causes, and restoration. Earth-Sci. Rev., 132, 1, 2014.

22. XU E.Q., ZHANG H.Q. Characterization and interaction of driving factors in karst rocky desertification: a case study from Changshun, China. Solid Earth, 5, 1329, 2014.

23. ZHANG J.Y., DAI M.H., WANG L.C., ZENG C.F., SU W.C. The challenge and future of rocky desertification control in karst areas in southwest China. Solid Earth, 7, 83, 2016.

24. YING B., XIAO S.Z., XIONG K.N., CHENG Q.W., LUO J.S. Comparative studies of the distribution characteristics of rocky desertification and land use/land cover classes in typical areas of Guizhou province, China. Environ. Earth Sci., 71, 631, 2014.

25. YAN X., CAI Y.L. Multi-scale anthropogenic driving forces of karst rocky desertification in Southwest China. Land Degrad. Dev., 26, 193, 2015.

26. LI Y.B., LI S.S., XU Q., LUO G.J. The evolution of karst rocky desertification for nearly 50 years in karst mountain,
Southwest China based on five cases study. Acta Ecol. Sin., 39, 8526, 2019.

27. SHI T.C., LI X.B.,Xin J.G.,XU X.H.Analysis of Farmland Abandonment at Parcel Level: A Case Study in the Mountainous Area of China. Sustainability, 8, 988, 2016.

28. ZHANG H, ZHANG S.M., LIU Z.D. Evolution and influencing factors of China's rural population distribution patterns since 1990. Plos One., 15, 626, 2020.

29. GUO Y.Z., QIAO W.F. Rural Migration and Urbanization in China: Historical Evolution and Coupling Pattern. Sustainability. 12, 7307, 2020

30. WANG C.C., ZHANG Y.Q., YANG Y.S., YANG Q.C., JING $\mathrm{H}$. What is driving the abandonment of villages in the mountains of Southeast China?. Land Degrad Dev., 30, $1183,2019$.

31. FANG F., LIU Y.S. The impact of population nonargriculturalization on cultivated land use type in traditional plain area. Hum. Geogr., 28, 100, 2013.

32. YANG R., LIU Y.S., LONG H.L. The study on nonagricultural transformation co-evolution characteristics of "population-land-industry": case study of the Bohai Rim in China. Geogr. Res., 34, 475, 2015.

33. LIU Y.S., LI Y.R. Spatio-temporal coupling relationship between farmland and agricultural labor changes at county level in China. Acta Geog. Sin., 65, 1602, 2010.

34. GIOVANNI Q., ROSANNA S., LUCA S., VWLIA D.P., ROSA C., VITO I., TIZIANA S. Long-term impacts of grazing management on land degradation in a rural community of Southern Italy: Depopulation matters. Land Degrad. Dev., 1, 2020.

35. CLAUDINE E., HELMUT H., KARL H.E., VERONIKA G. Socio-ecological trajectories in a rural Austrian region from 1961 to 2011: comparing the theories of Malthus and Boserup via systemic-dynamic modelling. Journal of Land Use Science., 15, 652, 2020.

36. STAFFAN R., MATS O., BJÖRN H. Cultivated land-a scarce commodity in a densely populated rural area in South Wollo, Ethiopia. Journal of Land Use Science., 12, $1,2017$.

37. SWEETING M.M. Reflections on the development of karst geomorphology in Europe and a comparison with its development in China. Z. Geomoph., 37, 127, 1993.

38. FENG Y.B., LONG H.L. The mechanism and countermeasures of solving spatial poverty based on rural population transfer and rural road construction: a case study of Guizhou province. Geogr. Res., 38, 2606, 2019.

39. WANG Q., LI Y.B., LIU Y.X. Comparative study of land use change in karst hillside-trough dam area. Res. Environ. Yangtze Basin, 28, 122, 2019.

40. LIU J.L., LIU Y.S., LI Y.R., HU Y.G. Coupling analysis of rural residential land and rural population in China during 2007-2015. J. Nat. Resour., 33, 1861, 2018.

41. YANG Y.M.N., ZHANG Y., YANG Q.S., LIU J., HUANG F. Coupling relationship between agricultural labor and agricultural production against the background of rural shrinkage: a case study of Songnen Plain, China. Sustainability, 11, 5804, 2019.

42. LONG H.L., ZOU J. Grain production driven by variations in farmland use in China: an analysis of security patterns. J. Resour. Ecol., 1, 60, 2010.

43. SONG X.Q., LI X.Y. Theoretical explanation and case study of regional cultivated land use function transition. Acta Geogr. Sin., 74, 992, 2019.

44. LIANG X.Y., LI Y.B. Spatiotemporal features of farmland scaling and the mechanisms that underlie these changes 
within Three Gorges Reservoir Area. J. Geogr. Sci., 29, $563,2019$.

45. Historiography Committee of Tujia and Miao Autonomous County in Yinjiang. Yinjiang Tujia Miao Autonomous County Annals. Guizhou People Press; 1992, 11.

46. WANG Q., LI Y.-B., HU X.-P., LI S.-S., CHEN H. Spatialtemporal evolution characteristics and driving mechanism of slope cultivated land use in karst trough valley area. J. Ecol. Rural Environ., 36, 53, 2020.

47. ZHANG Y.N., LONG H.L., MA L.L., TU S.S., CHEN K.Q. Geograph. Res., Research progress of urban-rural relations and its implications for rural revitalization. 38, 578, 2019.

48. WU Y.F., LIU Y.S., LI Y.S. Spatio-temporal coupling of demographic-landscape urbanization and its driving forces in China. Acta Geogr. Sin., 73, 1865, 2018.
49. LI R., WU Q.L., ZHANG J.J., WEN Y.Q., LI Q.G. Effects of Land Use Change of Sloping Farmland on Characteristic of Soil Erosion Resistance in Typical Karst Mountainous Areas of Southwestern China. Polish Journal of Environmental Studies, 28 (4), 2707, 2019.

50. RICARDO GRAU H., MITCHELL AIDE T. Are ruralurban migration and sustainable development compatible in mountain systems? Mt. Res. Dev., 27, 119, 2007.

51. MITCHELL AIDE T., RICARDO GRAU H. Globalization, migration, and Latin American ecosystems. Science, 305, 1915, 2004.

52. LIU Y.S. Research on the geography of rural revitalization in the new era. Geograph. Res., 38, 461, 2019.

53. YU Y., XU T.B., WANG T. Outmigration drives cropland decline and woodland increase in rural regions of Southwest China. Land., 9, 443, 2020. 
